\title{
Effect of herbal combination of triphala and garcinia cambogia extracts on anthropometric measurements and lipid profile in high fat diet induced obesity in rats
}

\author{
Vijay Kumar A. N. ${ }^{1 *}$, Vijay Thawani $^{2}$
}

Department of Pharmacology, ${ }^{1}$ DVVPF'S Medical College and Hospital, Ahmednagar, Maharashtra, ${ }^{2}$ People's College of Medical Sciences and Research Centre, Bhanpur, Bhopal, Madhya Pradesh, India

Received: 04 August 2019

Revised: 19 August 2019

Accepted: 20 August 2019

*Correspondence to: Dr. Vijay Kumar A. N., Email: vijaykumar.pharma@ gmail.com

Copyright: (C) the author(s), publisher and licensee Medip Academy. This is an openaccess article distributed under the terms of the Creative Commons Attribution NonCommercial License, which permits unrestricted noncommercial use, distribution, and reproduction in any medium, provided the original work is properly cited.

\begin{abstract}
Background: Obesity, occurring at epidemic rates globally, is a major risk factor for DM and CVD. Despite advances in understanding its pathogenesis, the pharmacotherapy for obesity remains limited for achievable weight loss, safety and tolerability of the medicines. Almost all approved medications for long term use in obesity treatment result in health issues. Due to the ADRs associated with many antiobesity drugs, the drug trials have focused on screening herbal medicines that are reportedly used in the treatment of obesity and which have minimal side effects.

Methods: In this study rats were divided into eight groups of six rats each. In the first approach, the rats were first made obese by feeding HFD for three weeks. In the second, treatment with the herbal extracts was given simultaneously with the HFD to the experimental rats. Rat were fed HFD for six weeks along with treatment of herbal extracts and the effect on their body weight, daily food intake and lipid-profile were evaluated.

Results: Results showed that rats fed HFD for a six week period, supplemented with herbal preparations of triphala and $G$. cambogia presented with significant reduction in body weight, energy intake, and improved the lipid-profile as compared to the rats fed with HFD group.

Conclusions: Our findings suggest that triphala and G. cambogia can counter the effects of HFD intake and have the potential for use as antiobesity agents with desirable body weight, food intake, fluid intake, and lipid-profile modulating properties.
\end{abstract}

Keywords: Obesity, Triphala, Garcinia cambogia, Body weight, Lipid-profile

\section{INTRODUCTION}

Obesity, a global epidemic, is a major risk factor for diabetes mellitus and cardio vascular diseases. Despite advances in understanding its pathogenesis, pharmacotherapy for obesity remains limited both in the degree of achievable weight loss and the tolerability of the medicines. Thus, discovery of novel targets and therapeutic agents is a focal point for combating this epidemic. $^{1,2}$
About 315 million people worldwide fall into the WHO defined obesity categories with a body mass index $(\mathrm{BMI})>30 .^{3} \mathrm{~A}$ person with a $\mathrm{BMI}>25$ is considered as overweight. The prevalence of overweight and obesity is increasing at an alarming rate in the economically developed and the developing countries. ${ }^{4,5}$ Epidemiologic studies indicate that overweight and obesity are important risk factors for DM, CVD, cancer and premature death. ${ }^{5}$ Obesity also contributes to shorter lifespan, depression and fall in quality of life. ${ }^{6,7}$ 
The latest obesity statistics of India shows that $75 \%$ of Indian women and $58 \%$ of Indian men are obese. The high prevalence of overweight and obesity, conjoint with their concomitant health risks, makes it particularly relevant worldwide public health challenge. Global projections estimate 1.12 billion individuals to be obese by the year 2030 and this rapid growth of obesity will occur in adults and children alike. ${ }^{8,9}$ The fundamental cause of obesity and overweight is a lack of energy balance between calories consumed and spent. Obesity results from complex interactions between genes and environmental factors such as diet, food components, and lifestyle can be viewed as an energy storage disorder in which weight gain results from an energy imbalance, with most of the excess calories stored as triglycerides in adipose tissue. ${ }^{10}$ The evidence for a genetic component in obesity is strong. ${ }^{11}$ The evidence include differences in prevalence between ethnic groups, higher fat concordance in monozygotic compared to dizygotic twins and 30-70\% BMI heritability between individuals. ${ }^{12-14}$ There are numerous theories explaining the genetics of obesity but there is no current consensus in the area as a consequence of the complex nature of obesity susceptibility. ${ }^{15}$ Adipose tissue affects energy homeostasis and cardiovascular health by releasing adipokines that regulate energy expenditure, food intake, insulin sensitivity and inflammation. $^{16}$ Obesity is associated with insulin resistance These all result in increased levels of fatty acids and glycerol, which aggravate insulin resistance in skeletal muscle and liver. ${ }^{17}$ Pharmacological approved medications associated with adverse drug reactions due to these ADR's, more recent drug trials have focused on screening the herbal medicines that have been reported to treat obesity and have minimal ADRs. This study was undertaken with an aim to evaluate the effect of herbal combination of Triphala and G. cambogia extracts in an experimental model of HFD induced obesity in albino rats.

\section{Mechanism of bioactive compounds}

Triphala is an ayurvedic herbal formula consisting of equal parts of three myrobalans, taken without seed: Amalaki (Emblica officinalis), Bibhitaki (Terminalia bellirica), and Haritaki (Terminalia chebula). ${ }^{18}$ The active constituents of Triphala study conducted by Gurjar et al, on Triphala and its constituents ameliorate visceral adiposity from a high fat diet in mice with diet induced obesity suggested that it can counter the effects of the high dietary intake of fats and is a potential antiobesity agents with desirable lipid profile modulating properties. $^{19,20}$

\section{Terminalia bellerica}

The ethanol extracts of $T$. bellerica fruits showed the presence of phytochemical active compounds such as tannins quinines phenols coumarines and flavanoids and phytosterols etc. $^{21}$

\section{Emblica officinalis}

E. officinalis contains flavonoids which reduce the levels of lipid in serum. A number of animal experiment report improved lipid profiles. ${ }^{22}$ Flavonoid extracts from the fruits of emblica inhibited synthesis of cholesterol via decreasing hepatic 3-hydroxy-3-methyl glutarylcoenzyme A (HMG-CoA) reductase and also enhanced degradation of cholesterol. ${ }^{22}$

In Ayurveda E. officinalis commonly known as Indian goose berry or amla or amalaki. It contains many important phytoconstituents like gallic acid, gallotanin, ellagic acid, corilagin etc. possess many therapeutic effects including antiobesity, anti-inflammatory, antidiabetic effects acting through their antioxidant and free radical scavenging properties. ${ }^{22}$ Previous studies stated that gallic acid is a phenolic compound of TPL which is selected as a bioactive marker due to its easy availability, and its anti-obesity property. ${ }^{23}$

\section{Terminalia chebula}

In T. chebula, $33 \%$ of the total phytoconstituents. ${ }^{24,25}$ Total eight compounds viz. gallic acid, methyl gallate, ethyl gallate, chebulagic acid, tetra- $O$-galloyl- $\beta$-Dglucose, ellagic acid, chebulinic acid and penta- $O$ galloyl- $\beta$-D-glucose from $T$. chebula were isolated on reverse phase chromatography, Fruit contains Phenolic Compounds, punicalagin, Terflavin-A, Terchebulin Girin, Antiobesity, Hypolipidaemia. ${ }^{28}$ Myrobalans bioactive compound of $T$. chebula act as antiobesity compound.

\section{Garcinia cambogia}

The active component of Garcinia cambogia is hydroxy citric acid (HCA), a compound that inhibits the enzyme ATP-citrate lyase, which is involved in endogenous lipid biosynthesis. Hydroxy citric acid also increases hepatic glycogen synthesis, suppresses appetite and decreases body weight gain. ${ }^{26}$ Hydroxy citric acid has helped to lower body weight and reduce fat mass in humans. ${ }^{26,27,29}$ Consequently, HCA reduces the transformation of citrate into acetyl coenzyme A, a step necessary for the formation of fatty acids in the liver. In addition, there is an increased production of hepatic glycogen in the presence of HCA, which may activate glucoreceptors leading to a sensation of fullness and reduced appetite. ${ }^{30}$ The increased bioavailability of serotonin is thought to be related to appetite suppressing effects of supplemental HCA. ${ }^{31}$ Another possible mechanism of action may be HCA's ability to down-regulate Leptin, an amino acid hormone that induces obesity and body weight. ${ }^{32}$

\section{METHODS}

\section{Place of work}

This study was carried out at Centre for Scientific Research and Development (CSRD), People's University, Bhopal, India. 


\section{Materials used}

Standardized aq extracts of Triphala and G. cambogia prepared freshly before experimentation.

Atorvastatin was used as positive control.

\section{Selection of herbal plants}

The plants Triphala and G. cambogia powders were selected as these are the most common ingredients of the anti-obesity herbal medicines. Also, some anti-obesity herbal medicines are just comprised of Triphala and $G$. cambogia powder.

\section{Plant powder collection}

The plant powders of Triphala and G. cambogia were procured from Mumbai based certified company manufactured by Pharmanza Herbal Pvt. Ltd.

\section{Animal experiments}

All the animal experiments were performed in accordance with the protocol approved by the Institutional Animal Ethics Committee of People's Medical College, People's University, Bhopal, MP, India.

\section{Selection of rat}

The animals were purchased from National Institute of Nutrition (NIN), Hyderabad, Telangana India.

\section{Strain, sex and age of rat}

Male Wistar rats, weighing between 150-200 grams were used for the study.

\section{Caging, housing and diet of animals}

The rats were maintained in appropriate conditions as per the CPCSEA Guidelines.

\section{Composition of experimental diets}

Standard rat chow Normal Diet (ND) and High Fat Diet (HFD) were purchased from NIN Hyderabad, Telangana.

\section{Preparation of herbal and standard drug formulation}

Stock preparation/ dose preparation

The herbal powders of Triphala, G. cambogia and Standard drug Atorvastatin were prepared freshly with Distilled water.

\section{Description about grouping, dosing and feeding}

Group 1 was received normal diet and served as normal control.

Group 2 was received HFD 45\% kcal\% fat throughout the study for 42 days.

Table 1: Normal diet (ND) composition.

\begin{tabular}{|ll|}
\hline Normal rat chow diet & $\% / 100 \mathrm{~g}$ \\
\hline Nutrients & 48.8 \\
\hline Carbohydrate & 21 \\
\hline Protein & 3 \\
\hline Fat & 0.8 \\
\hline Calcium & 0.4 \\
\hline Phosphorus & 5 \\
\hline Fiber & 13 \\
\hline Moisture & 8 \\
\hline Ash & 306.2 \\
\hline Total energy (kcal/100 g) & \\
\hline
\end{tabular}

Table 2: High fat diet (HFD) composition.

\begin{tabular}{|lll|}
\hline Product \#D12451 & gm \% & Kcal \% \\
\hline Protein & 24 & 20 \\
\hline Carbohydrate & 41 & 35 \\
\hline Fat & 24 & 45 \\
\hline Total kcal/gm & 4.73 & \\
\hline Ingredient & gm & Kcal \\
\hline Casein, 30 mesh & 200 & 800 \\
\hline L-cystine & 3 & 12 \\
\hline Corn starch & 72.8 & 291 \\
\hline Maltodextrin 10 & 100 & 400 \\
\hline Sucrose & 172.8 & 691 \\
\hline Cellulose, BW200 & 50 & 0 \\
\hline Soyabean oil & 25 & 225 \\
\hline Lard* & 177.5 & 1598 \\
\hline Mineral mix S10026 & 10 & 0 \\
\hline $\begin{array}{l}\text { DiCalcium } \\
\text { Phosphate }\end{array}$ & 13 & 0 \\
\hline Calcium carbonate & 5.5 & 0 \\
\hline $\begin{array}{l}\text { Potaassium citrate, } \\
\text { 1 H2O }\end{array}$ & 16.5 & 0 \\
\hline Vitamin mix V10001 & 10 & 40 \\
\hline Choline bitartrate & 2 & 0 \\
\hline FD\&C red dye \#40 & 0.05 & 0 \\
\hline Total & 858.15 & 4057 \\
\hline & & \\
\hline
\end{tabular}

Group 3 was received HFD for 21 days then from $22^{\text {nd }}$ day of the study till the end of the study Atorvastatin + HFD. This group acted as positive control group

Group 4 was received HFD for 21 days then from $22^{\text {nd }}$ day of the study till the end of the study Triphala extract + HFD. 
Group 5 was received HFD for 21 days then from $22^{\text {nd }}$ day of the study till the end of the study Garcinia cambogia extract + HFD
Group 6-8 were received HFD for 21 days then from $22^{\text {nd }}$ day of the study till the end of the study combination of aq extract of Garcinia cambogia and Triphala at 500, 1000 and $2000 \mathrm{mg} / \mathrm{kg}$ respectively + HFD.

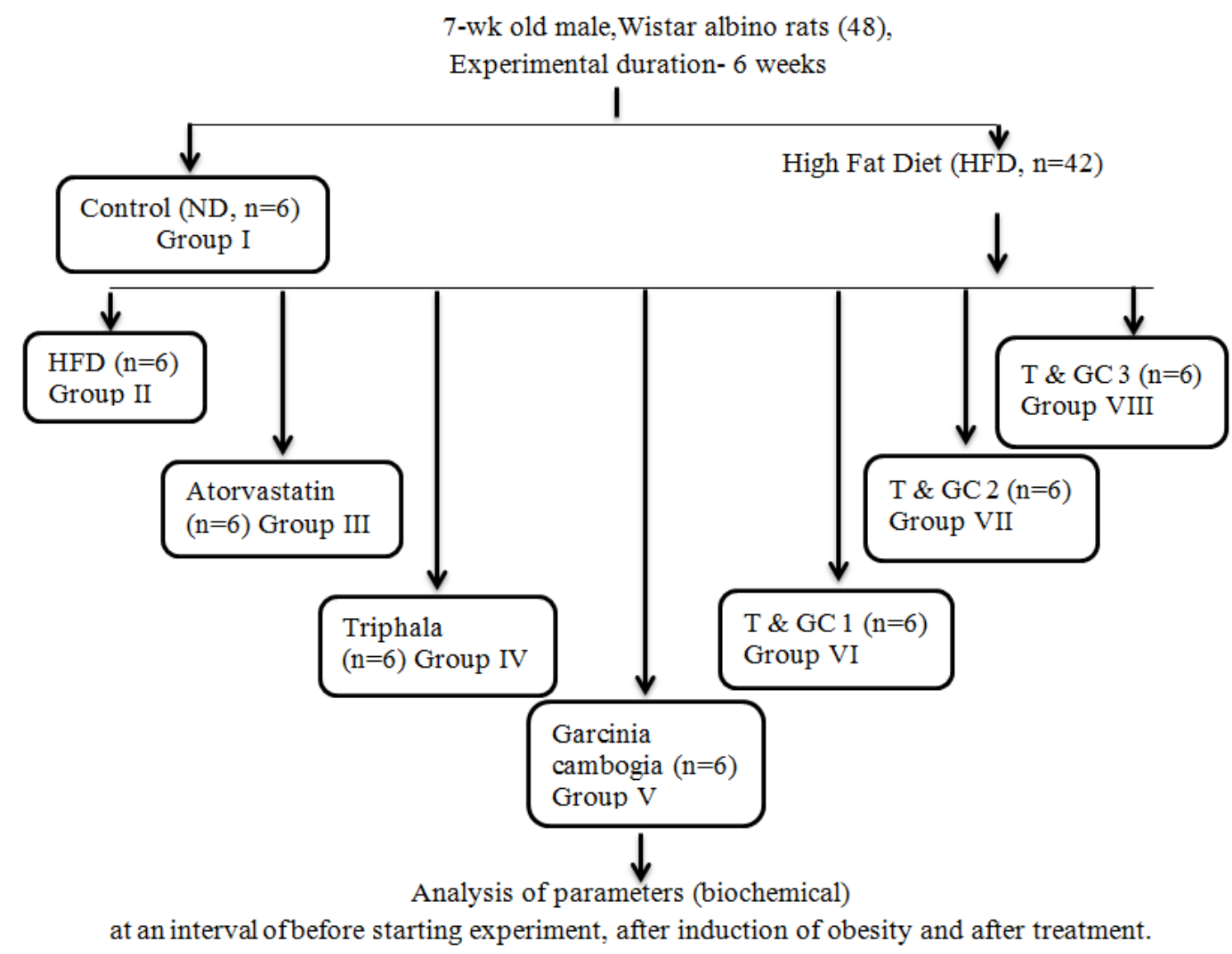

Figure 1: Experimental design (duration 6 weeks).

\section{Anthropometric measurements}

Anthropometric measurements like weight.

\section{Body weight}

Weight was recorded every week by using weighing scale.

\section{Food and fluid intake}

Food intake was calculated as gm/day/animal. Feed intake was recorded daily using the weighing scale.

\section{Excreta and urine}

Excreta and urine were calculated on daily in the morning by weighing their wet newspaper which consist of excreta and urine and this should be dried under the sun rays and again took the weight, first values (wet newspaper) subtracted from previous values (dried newspaper) the value which came finally that is actual value.

\section{Clinical test or blood parameter estimation}

Clinical investigations were performed on the plasma samples for lipid profile (Total cholesterol, TG, HDL, LDL and VLDL).

\section{RESULTS}

\section{Body weight}

The control group (group 1) which were fed with normal diet were slightly increased in their weight after three weeks, whereas the high fat diet (HFD) fed rats $181.16 \pm 14.85 \mathrm{gm}$ (group 2) rapidly increased more weight as compared to control group $158.83 \pm 7.13 \mathrm{gm}$. After the induction of obesity the treatments were started with Atorvastatin, Triphala extract, Garcinia cambogia extract, combination of Triphala and $G$. cambogia extracts. After the treatment with drug and extracts, atorvastatin slightly decreased in weight in obesity induced rats at the end of experiment the value is $164.33 \pm 14.94 \mathrm{gm}$, but when rats were treated with 
Triphala extract the value is $154.33 \pm 58.37 \mathrm{gm}, G$. cambogia extract the value is $164 \pm 4.24 \mathrm{gm}$ individually, rapidly decreased weight of HFD rat. When rats were treated with combination of Triphala and G. cambogia extracts with three deferent doses $(500 \mathrm{mg} / \mathrm{kg}, 1000$ $\mathrm{mg} / \mathrm{kg}, 2000 \mathrm{mg} / \mathrm{kg}$ ) among these three doses, at high dose $(2000 \mathrm{mg} / \mathrm{kg})$ the weight reduction occurs very rapidly the value is $157.66 \pm 13.48 \mathrm{gm}$ as compared to individual herbal extracts and low dose combinations i.e. at $500 \mathrm{mg} / \mathrm{kg}, 1000 \mathrm{mg} / \mathrm{kg}$ the values were $158.33 \pm 33.21$ gm and $173.66 \pm 6.68 \mathrm{gm}$ respectively.

\section{Food and fluid intake}

Food and fluid intake were normal in control group (group 1), whereas the high fat diet (HFD) fed rats (group 2) gradually increased $(p<0.05)$ food and fluid intake as compared to control group $(\mathrm{p}<0.05)$. After the induction of obesity when treatments were started with Triphala extract and Garcinia cambogia extract individually the food and fluid intake gradually decreased $(\mathrm{p}<0.05)$. Combination of Triphala and G. cambogia extracts when given to the obese rats drastic changes took place in food and fluid intake i.e. rapidly decreased food and fluid intake $(\mathrm{p}<0.05)$.

\section{Excreta and urine}

The excreta and urine excretion was normal in control group (group 1), whereas the high fat diet (HFD) fed rats (group 2) the excreta and urine excretion gradually increased as compared to the control group $(p<0.05)$. After the induction of obesity when treatments were started with Triphala extract, Garcinia cambogia extract individually the excreta and urine gradually decreased as compared to the control group $(\mathrm{p}<0.05)$ and combination group. During the treatment the excreta and urine excretion gradually decreased in all treatment groups because the intake of food and fluid was decreased during treatment $(\mathrm{p}<0.05)$.

\section{Total cholesterol}

Total cholesterol is diagnostic tool for cardiac problems. Total cholesterol is a condition that occurs when levels of cholesterol in blood are elevated enough to cause health problems such as heart disease.

The data indicated that after obesity induction of male rats, the level of total cholesterol got increased after 21days, where the value was found to be $50.57 \pm 8.65 * \mathrm{mg} / \mathrm{dl} \quad(\mathrm{p}<0.05)$ which is higher than the control value of $45.87 \pm 4.56 \mathrm{mg} / \mathrm{dl}(\mathrm{p}<0.05)$.

After the treatment with individual Triphala extract and G. cambogia extract the total cholesterol levels were decreased $29.06 \pm 18.78 \mathrm{mg} / \mathrm{dl}(\mathrm{p}<0.0001)$ and $38.34 \pm 9.32$ $\mathrm{mg} / \mathrm{dl}(\mathrm{p}<0.05)$. The co-treatment of combination extracts on total cholesterol concentration was found to be $29.84 \pm 9.12 \mathrm{mg} / \mathrm{dl}(\mathrm{p}<0.0001)$. This indicates that Triphala individual extract and high dose of combination extract treatment group showed decrease in total cholesterol level, hence combination treatment, at high dose exhibited protective effect against HFD elevated total cholesterol levels.

\section{HDL}

HDL is an indicator to assess cardiac function. In a series of experiments the level of HDL were evaluated. The level of HDL was decreased after 21 days HFD feed in albino male rats. It decreased from the control value of $113.53 \pm 21.66 \mathrm{mg} / \mathrm{dl}$ to $66 \pm 19.46 \mathrm{mg} / \mathrm{dl}$ after HFD $(\mathrm{p}<0.05)$. While the treatment with individual Triphala extract and $G$ cambogia extract and combination extracts were given to male rats for 21 days, the level of HDL were elevated to $95.5 \pm 24.78 \mathrm{mg} / \mathrm{dl}$ and $98.66 \pm 13.32$ $\mathrm{mg} / \mathrm{dl}$ respectively as compared to the combination treated animals indicating protective role of combination extract against HFD decreased HDL levels towards cardiac cells of the rats, where the values were found to be $145.33 \pm 38.76 \mathrm{mg} / \mathrm{dl}, \quad 172.16 \pm 60.48, \quad 168.66+19.4$ which were treated with three deferent doses of combination of Triphala and G. cambogia $(\mathrm{p}<0.0001)$.

In our study, significant rise in level of HDL was observed after administration of combination extracts in deferent doses in comparison with the baseline control group. The rise in HDL level is an unambiguous indication of cardiac disfunctioning caused by HFD induced obesity in rats.

\section{$L D L$}

The LDL, known as "bad" cholesterol, is one of the types of cholesterol in the blood. The LDL can create plaque deposits that build up on the walls of the blood vessels that serve the heart. Having high levels of LDL cholesterol raises the risk of heart disease, including atherosclerosis commonly known as hardening of the arteries. This serious disease raises the risk of heart attack, stroke, and death. The LDL is indicator to assess cardiac function. The value of LDL in the present study were found to be elevated more than the control group levels $40.93 \pm 7.21 \mathrm{mg} / \mathrm{dl}$ after high fat diet induced obesity in male Wistar rats in 21 days the value was $45.83 \pm 5.57 \mathrm{mg} / \mathrm{dl}$.

With the treatment with individual Triphala extract and $G$. cambogia extract the values decreased from the control value $30.75 \pm 8.72 \mathrm{mg} / \mathrm{dl}$ and $30.5 \pm 7.79 \mathrm{mg} / \mathrm{dl}(\mathrm{p}<0.05)$ respectively. Co-treatment with high dose of combination herbal extracts also showed further decreased in level of LDL where the values were found to be $31.13 \pm 8.20 \mathrm{mg} / \mathrm{dl}$ and $32.2 \pm 8.31 \mathrm{mg} / \mathrm{dl}$ respectively which is almost equal to control group $30.76 \pm 6.77 \mathrm{mg} / \mathrm{dl} \quad(\mathrm{p}<0.05)$. The determination of LDL in rats treated with $500 \mathrm{mg} / \mathrm{kg}$, $1000 \mathrm{mg} / \mathrm{kg}$ and $2000 \mathrm{mg} / \mathrm{kg}$ body weight with combination extracts showed significant decrease of LDL level towards the control value after 42 days exposure period indicating protective action of combination extracts against HFD induced elevated LDL. 
Vijay KAN et al. Int J Basic Clin Pharmacol. 2019 Sep;8(9):2004-2012

Table 3: Comparative table showing the anthropometric parameters in rat fed on the experimental diets for 6 weeks.

\begin{tabular}{|c|c|c|c|c|c|c|c|c|}
\hline Parameter & Control & $\begin{array}{l}\text { High fat diet } \\
\text { (HFD) }\end{array}$ & $\begin{array}{l}\text { HFD } \\
\text { +Atorvastatin }\end{array}$ & $\begin{array}{l}\text { HFD } \\
\text { + Triphala (T) }\end{array}$ & $\begin{array}{l}\text { HFD } \\
+ \text { G.Cambogia } \\
\text { (GC) }\end{array}$ & $\begin{array}{l}\text { HFD +(T+GC) } \\
\text { Combination } \\
(500 \text { mg/kg) }\end{array}$ & $\begin{array}{l}\text { HFD + (T+GC) } \\
\text { Combination } \\
(\mathbf{1 0 0 0 ~} \mathrm{mg} / \mathrm{kg})\end{array}$ & $\begin{array}{l}\text { HFD +(T+GC) } \\
\text { Combination } \\
(2000 \mathrm{mg} / \mathrm{kg}) \\
\end{array}$ \\
\hline \multicolumn{9}{|l|}{ Body weight } \\
\hline $1^{\text {st }}$ week & $158.83 \pm 7.13$ & $163 \pm 10.88$ & $159.83 \pm 5.87$ & $166.83 \pm 61.36$ & $166.5 \pm 11.708$ & $164.5 \pm 4.88$ & $168.16 \pm 8.58$ & $170.33 \pm 11.23$ \\
\hline $3^{\text {rd }}$ week & $190.33 \pm 5.98$ & $181.16 \pm 14.85$ & $165 \pm 9.93$ & $171.5 \pm 62.95$ & $183.83 \pm 7.88$ & $163.83 \pm 31.97$ & $180.83 \pm 9.62$ & $179.66 \pm 14.22$ \\
\hline $6^{\text {th }}$ week & $197.33 \pm 3.55$ & $203.66 \pm 15.56^{*}$ & $166.66 \pm 13.44$ & $164.16 \pm 60.00 * *$ & $164 \pm 4.24 * *$ & $159.5 \pm 32.43 * *$ & $173.66 \pm 6.68 \#$ & $162.33 \pm 15.33 * *$ \\
\hline \multicolumn{9}{|l|}{ Food intake } \\
\hline $1^{\text {st }}$ week & $6.63 \pm 6.49$ & $4.88 \pm 5.24$ & $5.58 \pm 5.58$ & $6.135 \pm 5.19$ & $5.99 \pm 4.89$ & $5.55 \pm 5.46$ & $7.27 \pm 6.36$ & $4.52 \pm 4.56$ \\
\hline $3^{\text {rd }}$ week & $7.88 \pm 7.52$ & $7.99 \pm 7.41 *$ & $10.83 \pm 10.0 *$ & $10.93 \pm 10.8^{*}$ & $9.86 \pm 10.4^{*}$ & $11.27 \pm 11.2^{*}$ & $10.32 \pm 10.1^{*}$ & $8.17 \pm 8.14^{*}$ \\
\hline $6^{\text {th }}$ week & $4.62 \pm 4.80$ & $6.26 \pm 6.33$ & $6.54 \pm 6.42$ & $8.09 \pm 8.01 *$ & $6.61 \pm 6.54 *$ & $6.63 \pm 6.51 *$ & $6.69 \pm 6.81 *$ & $4.75 \pm 4.74 * *$ \\
\hline \multicolumn{9}{|l|}{ Fluid intake } \\
\hline $1^{\text {st }}$ week & $27.66 \pm 28.1$ & $5.08 \pm 5.13$ & $28.41 \pm 28.4$ & $26.24 \pm 26.1$ & $12.75 \pm 12.4$ & $14.92 \pm 14.1$ & $18.18 \pm 19.5$ & $17.6 \pm 18.0$ \\
\hline $3^{\text {rd }}$ week & $16.43 \pm 14.8$ & $8.44 \pm 7.76^{*}$ & $14.94 \pm 14.8$ & $15.95 \pm 16.4$ & $19.99 \pm 20.3$ & $16.03 \pm 16.2$ & $26.06 \pm 26.6$ & $29.03 \pm 29.1 *$ \\
\hline $6^{\text {th }}$ week & $20.91 \pm 21.2$ & $6.26 \pm 6.28$ & $13.52 \pm 14.3$ & $10.52 \pm 11.8$ & $13.13 \pm 12.9$ & $14.3 \pm 14.16$ & $21.45 \pm 21.1$ & $19.4 \pm 19.3 *$ \\
\hline \multicolumn{9}{|l|}{ Excreta } \\
\hline $1^{\text {st }}$ week & $1.28 \pm 1.36$ & $1.06 \pm 1.10$ & $2.10 \pm 2.17$ & $1.96 \pm 1.93$ & $1.71 \pm 1.67$ & $1.22 \pm 1.09$ & $1.93 \pm 1.89$ & $1.93 \pm 1.86^{*}$ \\
\hline $3^{\text {rd }}$ week & $2.23 \pm 2.30$ & $2.33 \pm 2.42$ & $2.45 \pm 2.35$ & $2.52 \pm 2.44$ & $2.52 \pm 2.69$ & $2.52 \pm 2.63$ & $2.53 \pm 2.45$ & $2.40 \pm 2.3$ \\
\hline $6^{\text {th }}$ week & $2.05 \pm 2.22$ & $2.78 \pm 2.88$ & $2.21 \pm 2.23$ & $1.99 \pm 1.93^{*}$ & $1.92 \pm 1.77 *$ & $2.07 \pm 1.97$ & $2.24 \pm 2.18$ & $1.96 \pm 1.92 *$ \\
\hline \multicolumn{9}{|l|}{ Urine } \\
\hline $1^{\text {st }}$ week & $3.60 \pm 3.69$ & $5.88 \pm 6.23$ & $5.04 \pm 4.88$ & $5.53 \pm 5.57$ & $5.72 \pm 5.53$ & $5.52 \pm 5.76$ & $5.22 \pm 5.43^{*}$ & $5.21 \pm 5.33$ \\
\hline $3^{\text {rd }}$ week & $5.40 \pm 5.51$ & $6.68 \pm 6.91$ & $6.20 \pm 5.98$ & $6.25 \pm 6.45$ & $6.36 \pm 6.30$ & $6.28 \pm 6.37$ & $6.74 \pm 6.92$ & $6.77 \pm 7.08$ \\
\hline $6^{\text {th }}$ week & $5.46 \pm 5.49$ & $4.98 \pm 4.88$ & $4.79 \pm 4.65$ & $5.13 \pm 5.08$ & $5.54 \pm 5.36$ & $5.20 \pm 5.07$ & $5.77 \pm 5.69$ & $5.47 \pm 5.69$ \\
\hline
\end{tabular}

Values are mean \pm SEM; $n=6$ in each group. All means are statistically significantly different $\left(* * \mathrm{p}<0.0001,{ }^{*} \mathrm{p}<0.05\right)$

Table 4: Lipid profile in rats fed on the experimental diets for 6 weeks.

\begin{tabular}{|c|c|c|c|c|c|c|c|c|}
\hline Parameter & Control & $\begin{array}{l}\text { High Fat Diet } \\
\text { (HFD) }\end{array}$ & $\begin{array}{l}\text { HFD } \\
\text { +Atorvastatin }\end{array}$ & $\begin{array}{l}\text { HFD } \\
\text { +Triphala }(\mathrm{T})\end{array}$ & $\begin{array}{l}\text { HFD } \\
+ \text { G. Cambogia } \\
\text { (GC) }\end{array}$ & $\begin{array}{l}\text { HFD +(T+GC) } \\
\text { Combination } \\
(500 \text { mg/kg) }\end{array}$ & $\begin{array}{l}\text { HFD + (T+GC) } \\
\text { Combination } \\
(1000 \text { mg/kg })\end{array}$ & $\begin{array}{l}\text { HFD +(T+GC) } \\
\text { Combination } \\
(2000 \text { mg/kg) }\end{array}$ \\
\hline Total cholesterol & $45.87 \pm 4.56$ & $50.57 \pm 8.65 *$ & $21.51 \pm 4.95$ & $29.06 \pm 18.78 * *$ & $38.34 \pm 9.32 *$ & $34.92 \pm 10.12 *$ & $36.49 \pm 13.99 *$ & $29.84 \pm 9.12 * *$ \\
\hline HDL & $113.53 \pm 21.66$ & $66 \pm 19.46 * *$ & $110.16 \pm 12.81 * *$ & $95.5 \pm 24.78 * *$ & $98.66 \pm 13.32 * *$ & $114.5 \pm 13.00 * *$ & $172.16 \pm 60.48 * *$ & $168.66 \pm 19.4 * *$ \\
\hline LDL & $40.93 \pm 7.21$ & $30.76 \pm 6.77$ & $31.75 \pm 8.53$ & $30.75 \pm 8.72 *$ & $30.5 \pm 7.79 *$ & $31.13 \pm 8.20 *$ & $48.48 \pm 15.14$ & $32.2 \pm 8.31 *$ \\
\hline VLDL & $28.63 \pm 10.79$ & $25.72 \pm 8.65$ & $22.3 \pm 8.07$ & $16.86 \pm 10.66$ & $20.25 \pm 4.52 *$ & $26.51 \pm 6.83$ & $22.01 \pm 8.26$ & $25.43 \pm 5.03$ \\
\hline Triglyceride & $158.82 \pm 15.50$ & $48.41 \pm 9.43$ & $52.16 \pm 7.78$ & $31.87 \pm 5.76^{*}$ & $59.22 \pm 9.58$ & $115.65 \pm 8.77$ & $68.08 \pm 17.04$ & $38.61 \pm 1.87 *$ \\
\hline
\end{tabular}

Values are mean \pm SEM; $n=6$ in each group. All means are statistically significantly different $\left(* * p<0.0001,{ }^{*} p<0.05\right)$ 


\section{$V L D L$}

The VLDL is one of the types of cholesterol in the blood. The VLDL can create deposits known as plaques that build up on the walls of the blood vessels that serve the heart. Having very high levels of VLDL raises the risk of heart disease, including atherosclerosis commonly known as hardening of the arteries. This serious disease raises the risk of heart attack, stroke, and death.

The VLDL is an indicator to assess cardiac function. The value of VLDL in our study was found to be decreased after HFD induced obesity in male Wistar rats in 21days, as $25.72 \pm 8.65 \mathrm{mg} / \mathrm{dl}$, and it was less than the control group levels. With the treatment of individual Triphala extract and G. cambogia extract, the value decreased from the control value of $16.86 \pm 10.66 \mathrm{mg} / \mathrm{dl}$ and $20.51 \pm 4.52$ $\mathrm{mg} / \mathrm{dl}$ respectively. Treatment with high dose combination of two herbal extracts showed decrease in VLDL where the value was found to be, $26.51 \pm 6.83$ $\mathrm{mg} / \mathrm{dl}, \quad 22.01 \pm 8.26 \mathrm{mg} / \mathrm{dl}$ and $25.01 \pm 5.03 \mathrm{mg} / \mathrm{dl}$ respectively which is lesser then the control group.

Thus the determination of VLDL in rats treated with combination extracts showed decrease in VLDL level towards the control value after 42 days exposure, indicating protective action of combination extracts against HFD induced elevated VLDL.

\section{Triglycerides}

The triglycerides (TG) are form of fat found in the blood, similar to cholesterol. Having high triglyceride levels raises the risk of developing heart disease, including the risk of heart attack. High TG levels are sometimes a sign of a condition known as metabolic syndrome, a group of problems that includes obesity, high blood pressure, elevated blood sugar, and high cholesterol.

The TG is another important diagnostic tool for cardiac toxicity. We found TG to be decreased than the control group levels $158.82 \pm 15.50 \mathrm{mg} / \mathrm{dl}$ after high fat diet induced obesity in male Wistar rats in 21 days where the value was $48.41 \pm 9.43 \mathrm{mg} / \mathrm{dl}$ while with the treatment with individual Triphala extract and $G$ cambogia extract the value decreased from the control value of $31.87 \pm 5.76$ $\mathrm{mg} / \mathrm{dl}(\mathrm{p}<0.05)$ and $59.22 \pm 9.58 \mathrm{mg} / \mathrm{dl}$ respectively. Cotreatment with high dose of combination herbal extracts also showed significant decrease in TG levels which were found to be, $38.61+1.87 * \mathrm{mg} / \mathrm{dl}(\mathrm{p}<0.05)$.

Thus the determination of TG in rats treated with 2000 $\mathrm{mg} / \mathrm{kg}$ body weight with combination extracts showed significant decrease of TG level after 42 days exposure, indicating protective action of combination extracts against HFD induced elevated TG.

\section{DISCUSSION}

This study involves the screening of herbal extracts in the treatment of obesity. The present study assessed the preventive as well as the curative aspect of the herbal powders together as a formulation or individually in HFD induced rat model for obesity. In this study anthropometric markers along with the effect on lipid profile were assessed. Interestingly these herbals proved to be significantly effective in preventing as well as curing the metabolic syndrome i.e. obesity. Many research reports have documented Triphala and $G$. cambogia being effective against obesity but these results have never been put under scientific investigation. Further, the effect of combination of Triphala and $G$. cambogia has never been tested for obesity.

In both the experiments, combination of Triphala and $G$. cambogia proved to be more effective. In the present study, a suppressed food intake does not appear to be the only cause of weight loss in the rats treated with herbal preparations, since in addition to food intake in these groups compared to the HFD rats. The initial body weights of all the groups were not significantly different (average body weight, 150-200 g); however, after three weeks, body weights began to diverge in the preventive experiment. The body weight of ND group was significantly lower as compared to the HFD group. In the treatment groups, the body weight was significantly less as compared to the HFD group (Table 3 ). In the curative experiment, body weight began to diverge after the fifth week of the experimental duration i.e. after two weeks of the start of the treatment. The average weight gain and food intake were significantly higher in the HFD group than in the ND and treatment groups (Table 3). As per ayurvedic texts, Triphala can dissolve accumulated fat within the body. ${ }^{33}$ Triphala and G. cambogia can reduce food consumption in human and rodent models of obesity, possibly by diverting carbohydrates and fatty acids that would have become fat in the liver, into hepatic glycogen. ${ }^{34,35}$ This metabolic change may send signal to the brain resulting in a reduced appetite. The active component of $G$. cambogia is HCA, a compound that inhibits the enzyme ATP-citrate lyase, which is involved in endogenous lipid biosynthesis. In addition, to this there is an increased production of hepatic glycogen in the presence of HCA, which may activate glucoreceptors leading to a sensation of fullness and reduced appetite.

Phytochemical analysis of Triphala constituents shows the presence of polyphenols, tannins, flavanoids and glycosides; out of which tannins are in the major proportion. Tannin content was reported to be $21 \%$ in $T$. bellerica, $30-32 \%$ in $T$. chebula and $28 \%$ in $\mathrm{E}$. officinalis. $^{35}$

Researchers have shown the presence of other polyphenols viz. ellagic acid and gallic acid. Recent studies have shown that presence of combination of marker compounds (i.e., gallic acid and ellagic acid) had the same antiobesity effect as the use of the whole crude extract thus indicating that gallic acid, and ellagic acid represents the majority, if not all, of the responsible components that cause significant weight loss. ${ }^{36-38}$ 
Although the mechanisms of action are unknown, it is assumed that the observed anti-obesity effect is probably caused by multiple components with possible synergistic interactions at multiple sites of actions by combination herbal treatment. ${ }^{39}$ Ours is the first report on the antiobesity effect of combination of Triphala and $G$. cambogia on HFD induced obese rat model. The herbal combination proved to be both "preventive" (prevented the weight gain when the treatment was given along with the high fat diet) as well as "curative" (caused the weight loss once the obese high fat-fed rat were given the treatment). The combination reduced significantly the body weight gain of the HFD induced obese rat model in the "preventive mode" experiment. In the second experiment, "curative mode", the combination treatment was observed to reduce significantly the body weight gain of the HFD induced obese rat model.

It is well documented that the relative weight of the total visceral fat-depots of the rat fed the HFD was significantly greater than the value for the ND rat, due to HFD the accumulation of visceral fat is also more.

\section{CONCLUSION}

The aim of this study was the antiobesity effect of herbal of combination of Triphala and G. cambogia on high fat diet induced obesity in rat. Ayurveda recognizes obesity as an imbalance in three doshas: vata, pitta and kapha. Triphala and G. cambogia are the commonly used herbal medicines in Ayurveda. Use of combination of Triphala and $G$. cambogia as anti-obesity remedies has not been yet tested clinically. This forms the basis of choosing combination of Triphala and G. cambogia for our study. As per Ayurvedic texts, amla can dissolve accumulated fat within the body. Triphala and G. cambogia can reduce food consumption in humans and rodent models of obesity, possibly by diverting carbohydrates and fatty acids that would have otherwise been stored as fats in the liver as hepatic glycogen.

The work presented in this study focuses largely on the changes in anthropometric parameters, and lipid profile. The HFD significantly increased the body weight of HFD rats as compared to ND rats. The herbal treatment showed significant reduction in body weight along with reduction in energy intake. The treatment significantly improved the clinical parameters as compared to the HFD group. The HDL concentration was significantly improved with the given herbal intervention and decreased in levels of LDL, VLDL, Triglyceride and Total cholesterol after the treatment with combination of triphala and G. cambogia. Triphala and $G$ cambogia individual treatments were also effective in reducing the HFD-induced weight gain but to a lesser extent as compared to combination of herbal extracts. The research team herein reports for the first time the in vivo antiobesogenic effects of combination of Triphala and G. cambogia.

\section{ACKNOWLEDGEMENTS}

The culmination of this study is result of the research, blessings, guidance and friendship from many people with whom I have been associated. It is a pleasure to convey my gratitude to all of them herein.

I express my sincere gratitude to my supervisor, Prof. Dr.Vijay Thawani, Professor and Head, Department of Pharmacology, People's College of Medical Sciences and Research Centre, Bhopal, who has ploughed through preliminary versions of my thesis, making critical suggestions and posing challenging questions. It was his keen eye on the logistics and planning due to which this thesis has taken its present shape in time. It is a privilege to have him as my mentor and be trained under his watchful guidance. His scientific acumen and intuition has made him as a constant oasis of ideas, and working with him has been inspirational for my growth as a student and a researcher.

This work is a result of an active support from Dr. Abin Mani, Senior Scientist, Centre for Scientific Research and Development (CSRD), People's University for his help in synopsis preparation and animal experimentation. I thank Dr. Kamal Zaidi for taking care of rats and for helping me in clinical parameter analysis.

Funding: No funding sources

Conflict of interest: None declared

Ethical approval: The study was approved by the Institutional Animal Ethics Committee (IAEC) of People's Medical College, People's University, Bhopal, Madhya Pradesh, India

\section{REFERENCES}

1. Chavarro JE, Toth TL, Wright DL, Meeker JD, Hauser R. Body mass index in relation to semen quality, sperm DNA integrity, and serum reproductive hormone levels among men attending an infertility clinic. Fertil Steril. 2010;93(7):2222-31.

2. Mayes JS, Watson GH. Direct effects of sex steroid hormones on adipose tissues and obesity. Obes Rev. 2004;5(4):197-216.

3. Caterson I, Gill T. Obesity:epidemiology and possible prevention. Best Pract Res Clin Endocrinol Metabol. 2003;16(4):595-610.

4. Abelson P, Kennedy D. The obesity epidemic. Science 2004;304(5676): 1413.

5. Haslam D, James P. Obesity. Lancet. 2005;366(9492):1197-209.

6. Roos C, Lidfeldt J, Agardh C, Nyberg P, Nerbrand C, Samsioe G, et al. Insulin resistance and self-rated symptoms of depression in Swedish women with risk factors for diabetes:the Women's Health in the Lund Area study. Metabolism. 2007;56(6):825-9.

7. Roth J, Qiang X, Marbán S, Redelt H, Lowell B. The obesity pandemic: where have we been and where are we going? Obes Res. 2004;12(2):88-101. 
8. Kelly T, Yang W, Chen CS, Reynolds K, He1 J. Global burden of obesity in 2005 and projections to 2030. International J of Obesity. 2008;32(9):1431-7.

9. Wang $\mathrm{Y}$, Beydoun M, Liang L, Caballero B, Kumanyika S. Will all Americans become overweight or obese? Estimating the progression and cost of the US obesity epidemic. Obesity (Silver Spring). 2008;16(10):2323-30.

10. Hill J, Peters J. Environmental contributions to the obesity epidemic. Science. 1998;280(5368):1371-4.

11. Friedman J. Modern science versus the stigma of obesity. Nat Med. 2004;10(6):563-9.

12. Knowler W, Pettitt D, Saad M, Bennett P. Diabetes mellitus in the Pima Indians: incidence, risk factors and pathogenesis. Diabetes Metab Rev. 1990;6(1):127.

13. Stunkard A, Foch T, Hrubec Z. A twin study of human obesity. JAMA. 1986;256(1):51-4.

14. Hebebrand J, Friedel S, Schäuble N, Geller F, Hinney A. Perspectives:molecular genetic research in human obesity. Obes Rev. 2003;4(3):139-46.

15. Walley A, Asher J, Froguel P. The genetic contribution to non-syndromic human obesity. Nat Rev Genet. 2009;10(7):431-42.

16. Korner J, Woods S, Woodworth K. Regulation of energy homeostasis and health consequences in obesity. Am J Med. 2009;122(4-1):S12-8.

17. Boden G. Role of fatty acids in the pathogenesis of insulin resistance and NIDDM. Diabetes. 1997;46(1):3-10.

18. Tan GD, Goossens GH, Humphreys SM, Vidal H, Karpe F. Upper and lower body adipose tissue function:a direct comparison of fat mobilization in humans. Obes Res. 2004;12(1):114-8.

19. McKeigue PM, Shah B, Marmot MG. Relation of central obesity and insulin resistance with high diabetes prevalence and cardiovascular risk in South Asians. Lancet. 1991;337(8738):382-6.

20. Chinetti G, Fruchart JC, Staels B. Peroxisome proliferator-activated receptors and inflammation: from basic science to clinical applications. Int J Obes Relat Metab Disord. 2003;27(3):41S-S45.

21. Anindita D, Sikha B, Biswajit D. Pharmacological activities of Baheda (Terminalia bellerica):A review. J of Pharmacognosy Phytochem. 2016;5(1):194-7.

22. Yokozawa T, Kim HY, Kim HJ, Okubo T, Chu DC, Juneja LR. Amla(Emblica Officinalis Gaertn.) prevents dyslipidaemia and oxidative stress in the ageing process. Br J Nutr. 2007;97(6):1187-95.

23. Kamali SH, Khalaj AR, Shirin HR, Esfehani MM, Kamalinejad M, Larijani B. A systematic review of the antioxidant, anti-diabetic, and anti-obesity effects and safety of triphala herbal formulation. 2013;7(14):831-44

24. Juang LJ, Sheu SJ, Lin TC. Determination of hydrolyzable tannins in the fruit of Terminalia chebula Retz. by high-performance liquid chromatography and capillary electrophoresis. J Sep Sci. 2004;27(9):718-724.
25. Chattopadhyay RR, Bhattacharyya SK. Plant Review Terminalia chebula. Pharmacognos. Rev. 2007;23:145-50.

26. Kirby J, Philip N, Howles Y. Hypolipidemic effect of triphala in experimentally induced hypercholesteremic rats. J Lipid Res. 2004;45(1):89-98.

27. Ferrara L. The garcinia cambogia in phytotreatment of obesity:activities of the hydroxycitric acid. European Scientific J. 2014;10(21):291-301.

28. MaruthappanVK, Sakthi S, Hypolipedimic activity A Haritaki in atherogenic diet induced hyperlypidemic rats. J. Adv Pharm tech Res. 2010;1(2):229-35.

29. Sergio W. A natural food, the malabar tamarind, may be effective in the treatment of obesity. Med Hypotheses. 1988;27(1):39-40.

30. Lowenstein JM. Effect of (-)-hydroxycitrate on fatty acid synthesis by rat liver in vivo. J Biol Chem. 1971;246(3):629-32.

31. Ohia SE. Safety and mechanism of appetite suppression by a novel hydroxycitric acid extract (HCA-SX). Mol Cell Biochem. 2002;238(1-2):89103.

32. Dagogo JS. Human leptin regulation and promise in pharmacotherapy. Curr Drug Targets. 2001;2:18195.

33. Kizhakkeveettil A, Jayagopal PS, Rose KK. Hypercholesterolemia and Ayurvedic Medicine:A Case Report. Topics in Integrative Health Care. 2011;2(2).

34. Murali YK, Anand P, Tandon V, Singh R, Chandra R, Murthy PS. Long-term effects of Terminalia chebula Retz. on hyperglycemia and associated hyperlipidemia, tissue glycogen content and in vitro release of insulin in streptozotocin induced diabetic rats. Exp Clin Endocrinol Diabetes. 2007;115(10):641-6.

35. Vani T, Rajani M, Sarkar S, Shishoo CJ. Antioxidant properties of the ayurvedic formulation triphala and its constituents International. J Pharmacognosy. 1997;35(5):313-7.

36. Cabrera C, Artacho R, Gimenez R. Beneficial Effects of Green Tea - A Review. J. Am. Coll. Nutr. 2006;25(2):79-99.

37. Wolfram S, Wang Y, Thielecke F. Anti-obesity Effects of Green Tea:From Bedside to Bench. Mol. Nutr. Food Res. 2006;50(2):176-87.

38. Thielecke F, Boschmann M. The Potential Role of Green Tea Catechins in the Prevention of Metabolic Syndrome - A Review. Phytochem. 2009;70(1):1124.

39. Li HB, Jiang Y, Wong CC, Cheng KW, Chen F. Evaluation of Two Methods for the Extraction of Antioxidants from Medicinal Plants. Anal Bioanal Chem. 2007;388(2):483-8.

Cite this article as: Vijay KAN, Thawani V. Effect of herbal combination of triphala and garcinia cambogia extracts on anthropometric measurements and lipid profile in high fat diet induced obesity in rats. Int J Basic Clin Pharmacol 2019;8:2004-12. 